Article

\title{
Driving Behaviour in Depression: Findings from a Driving Simulator Study
}

\author{
Vagioula Tsoutsi ${ }^{1,2, *}$, Dimitris Dikeos ${ }^{1}$, Maria Basta ${ }^{3} \mathbb{C}$ and Maria Papadakaki ${ }^{2}$ \\ 1 Sleep Study Unit, Eginition Hospital, First Department of Psychiatry, Medical School, \\ National and Kapodistrian University of Athens, 11528 Athens, Greece; ddikeos@med.uoa.gr \\ 2 Laboratory of Health and Road Safety, Department of Social Work, Hellenic Mediterranean University, \\ Heraklion, 71004 Crete, Greece; mpapadakaki@yahoo.gr \\ 3 Department of Psychiatry, University Hospital of Heraklion, 71110 Crete, Greece; mbasta73@gmail.com \\ * Correspondence: vagia.ts@gmail.com; Tel.: +30-693-8147-615
}

Received: 4 September 2019; Accepted: 12 October 2019; Published: 16 October 2019

check for updates

\begin{abstract}
Depression is characterized by mental, emotional and executive dysfunction. Among its symptoms, sleep disturbance and anxiety are very common. The effects of depression and its treatment may have an impact on driving behaviour. In order to evaluate driving performance in depression, 13 patients and 18 healthy controls completed questionnaires and scales and were tested in a driving simulator. Driving simulator data included lateral position (LP), speed and distance from the preceding vehicle. History of collisions was associated with depression, body mass index (BMI) and next-day consequences of sleep disturbance. Aggressive driving was associated with fatigue and sleep disturbances. Concerning driving simulator data, a reduced ability to maintain constant vehicle velocity was positively correlated to BMI and insomnia. An LP towards the middle of the road was associated with anxiety. On the other hand, an LP towards the shoulder was associated with depression and next-day consequences of sleep disturbance, while a positive correlation was found between distance from the preceding vehicle and use of drugs with potential hypnotic effects; both these findings show that patients suffering from depression seem to realize the effects of certain symptoms on their driving ability and thus drive in a more defensive way than controls.
\end{abstract}

Keywords: depression; sleep disorders; anxiety; drugs; driving; driving simulator

\section{Introduction}

Sleep and vigilance, important factors which may have an impact on driving behaviour, are often affected by mental disorders and the effects of their treatment. Sleep disorders, excessive daytime sleepiness and drowsiness are the most common factors that lead to road collisions [1-4]. According to epidemiological studies, almost $50 \%$ of the population will experience some kind of mental illness at least once in their life, while $25 \%$ have experienced a mental disorder over the past year [5].

Depression and road accidents are among the four leading causes of morbidity and mortality in developed countries [6]. Depression, a quite common disease in the general population, is characterized by mental, emotional and executive dysfunction [7]. Depression affects psychomotor and cognitive skills [8], while its symptoms or adverse reactions to antidepressant treatment, which often include lethargy and other sleep disorders, may also affect functional level and have an impact on driving behaviour [7,9].

Driving is an almost daily activity for a large part of the world's population. It is a very complex process due to the limited time that the driver has in order to make a decision and react properly. There are specific abilities that are essential for driving; among them, visual perception, selective attention, vigilance, reactivity and stress tolerance are the most important [10]. 
The majority of studies on road accidents have focused on socio-demographic characteristics and general personality, as well as driving competence [11,12]. While a small number of research studies have examined driving performance in relation to depression and anxiety, their main focus is often on the effects of the drugs, especially antidepressants and benzodiazepines $[7,10,13,14]$.

The driving simulator is a device which reliably reflects driving performance on the road and has been used in studies under a variety of conditions potentially affecting driving ability (e.g., alcohol consumption and blood levels, sleep deprivation, sleep apnea, use of mobile phone, etc.) [15-17].

The aim of the current study is to evaluate driving performance in depression on a driving simulator, taking into account levels of anxiety and sleep disturbance.

\section{Methods}

\subsection{Participants and Design}

The current study is a comparison of driving performance in depressed patients and a group of healthy controls. A sample of 13 depressed patients (all but one receiving antidepressant treatment) and 18 healthy controls participated in this study. The patients who participated were diagnosed and monitored by a psychiatrist.

Participants were included if they met the following criteria: Age 18 years or older, possession of a driving license, driving regularly and informed consent prior to participation. The study had two parts. In the first part, participants were interviewed by the researcher and were asked to complete questionnaires and scales; in the second part they were evaluated for their driving on a VS500M driving simulator (Virage Simulation, Canada).

\subsection{Questionnaires}

The choice of questionnaires/scales was based on findings of previous literature which have shown that sleep disturbance [1-4,9], day-time somnolence [1-4], low functioning [10] and driving behaviour [11-13] are very often factors underlining road traffic collisions, and on the fact that the scales we used in the study have been extensively utilized in studies of depressed patients as well as in studies of driving performance.

\subsubsection{Demographics and Other Data}

A questionnaire was used to document information about age, sex, marital status, educational level, profession, years since acquiring driver's license and history of collisions (irrespective of responsibility) involved as a driver.

\subsubsection{Medical History}

Information about history of mental and somatic disorders, current medications and current mental state were recorded.

\subsubsection{Hospital Anxiety and Depression Scale (HADS)}

The hospital anxiety and depression scale was designed by Zigmond and Snaith [18]. It is a self-reported scale that consists of 14 items and each of these items has four possible answers (0-3). It is designed in order to estimate separately anxiety (HADS-A) and depression (HADS-D).

\subsubsection{Athens Insomnia Scale (AIS)}

The Athens insomnia scale is a self-reported questionnaire [19] estimating the difficulty in sleep according to ICD-10 criteria [20]. It consists of eight four-point Lickert scale (0-3) items, the first five of them pertaining to sleep induction, nighttime awakenings, final awakening, total sleep duration and quality of sleep, while the last three cover next-day wellbeing, functioning capacity and sleepiness during the day. 


\subsubsection{Fatigue Severity Scale (FSS)}

The fatigue severity scale was designed in 1989 [21]. It is a self-reported questionnaire consisting of nine items which estimate the severity of the symptoms of fatigue. The score of each item ranges from 1 to 7 , where 1 is "strongly disagree" and 7 is "strongly agree".

\subsubsection{Sleep Disturbances Questionnaire}

This questionnaire was designed by the Sleep Study Unit of Eginition University Hospital. It is a self-reported questionnaire consisting of six items regarding the quality and disturbances of sleep (overall sleep satisfaction, movements, snoring, breathing, difficulty in sleep, drowsiness during the day, nightmares). The score of each item ranges from 0 to 3 , where 0 is "never" and 3 is "always".

\subsubsection{Social and Occupational Functioning Assessment Scale (SOFAS)}

This scale reflects the estimation of the overall level of functioning by a clinician [22]. The rating ranges from 0 (lowest functioning) to 100 . Both social and occupational functioning are considered, as well as any impairments due to physical or mental disorders. In order to be considered, the impairment should be the effect of a health problem and not just a consequence of a lack of opportunity or of an environment.

\subsubsection{Driver Stress Inventory (DSI)}

The driver stress inventory (DSI) aims to detect drivers' vulnerability to stress reactions while driving. It is an extension of the driving behaviour inventory (DBI) [23]. In this study we use the version of Qu et al. [24].

It is a self-reported questionnaire consisting of 48 items which estimates in five separate subscales aggression, dislike of driving, hazard monitoring, thrill seeking and proneness to fatigue. The score of each item ranges from 0 to 10 , where 0 is "not at all" and 10 is "very much".

\subsection{Driving Simulator}

Driving Simulator «Virage VS500M» (Virage Simulation, Canada) features advanced simulation software and uses a sophisticated driving environment with real auto parts to provide a realistic feel in all functions. Driving Simulator's environment appears in Figure 1.

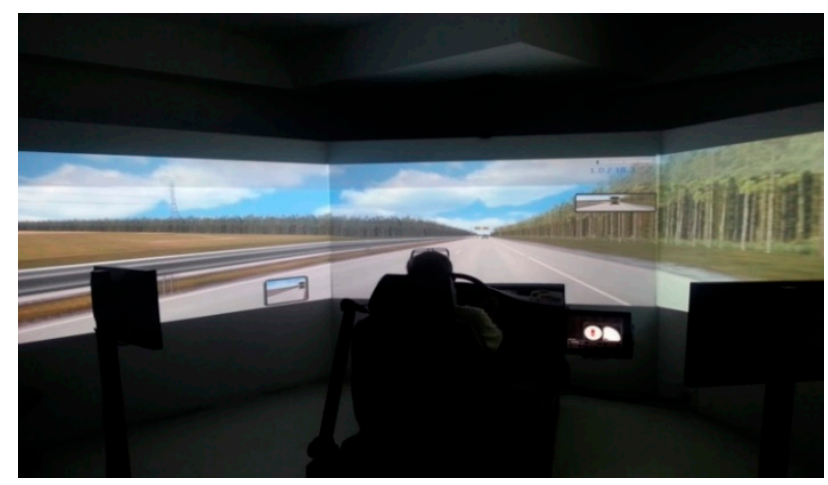

Figure 1. The driving simulator's environment.

It consists of an open cabin including the driver's seat, the center console, a fully functional instrument cluster, lights and warning lights as well as motion and vibration systems. Three-dimensional graphics are projected into three wide screens covering a 180 degree field of view and located in front of the cabin. The mirrors are inserted in the main screen. The driving simulator has a variety of different scenarios where the user can drive in many different environments, such as in the city, on the motorway and on the mountains, in different weather conditions, etc. 
The Virage Series Simulators have been validated for transfer of training in control skills to real life with satisfactory results, although caution should be taken, since the only relevant study of the Virage Series refers to a truck simulator and not the car simulator which was used in the present study [25].

In this study we used three of the available scenarios. In scenario 1 participants drove without interference in a motorway environment for $5 \mathrm{~min}$. In scenario 2 participants drove also for $5 \mathrm{~min}$ in a motorway environment but in this scenario an event (sudden obstacle in the road) was designed in order to record the participants' reaction. Participants were not informed beforehand about the event. Scenario 3 was a 5-minute drive in an urban environment. A 3-minute accustomization driving period preceded the three scenarios.

\subsection{Statistical Analysis}

The SPSS 23.0 statistical package (IBM SPSS Statistics for Windows, Version 23.0. Armonk, NY, USA: IBM Corp., 2015) was used to process the data. Multiple linear backward regressions were performed for each dependent variable and the final regression model was retained. For the backward regressions all subjects were pooled together; to make between-group comparisons clear, however, the means $( \pm \mathrm{SD})$ of the group of depressed patients and of that of the controls were calculated and are presented in a separate table.

The independent variables were: Gender, age, marital status, variable patient/control, body mass index (BMI), years of possession of a driving license, drugs with potential hypnotic effects, score of HADS depression and HADS anxiety separately, total score of Athens insomnia scale (AIS), sum score of items 7 and 8 of Athens insomnia scale (next-day consequences of sleep disturbance), total score of fatigue severity scale (FSS), total score of sleep disturbances questionnaire and total score of SOFAS functioning scale.

The dependent variables were: History of self-reported involvement in road accidents, scores of the five subscales of the questionnaire for stress assessment during driving (DSI) and data extracted from the Driving Simulator, namely lateral position (LP), inability to keep a steady lateral position (expressed as standard deviation of lateral position as a metric of each participant), vehicle velocity (both as mean car speed of each participant, as well as inability to keep a steady speed expressed as standard deviation of car speed as a metric of each participant) and distance from the preceding vehicle. The lateral position is the distance of the middle of the vehicle from the middle of the lane in which the vehicle is driven. It varies from -1 to 1 with -1 signifying the car being at the limit of the lane towards the middle of the road (to the left in roads where traffic keeps to the right) and 1 signifying the car being at the limit of the lane towards the shoulder (to the right in roads where traffic keeps to the right). The width of the simulator's lane is $350 \mathrm{~cm}$. In scenarios with multiple lanes -1 signifies a position towards the faster lane and 1 a position towards the slower lane.

Statistical significance level was set at $5 \%$.

\section{Results}

\subsection{Main Characteristics of the Sample}

Table 1 displays the main characteristics of the 31 participants who were included in the study. The majority of participants were women, about half of the total sample were married or cohabited and the mean age was 46 years old (range 29 to 69). Twenty-seven participants were employed, all but one at a daytime job. Moreover, 27 had a higher education degree and 24 lived in an urban area. Mean time from acquiring a driver's license was 22.77 years (range 6 to 49 ).

\subsection{Physical and Mental Characteristics of the Sample}

The mean body mass index (BMI) was 25.06 (range 20 to 52, Table 1). Eighteen participants had no symptoms of depression and they had never received antidepressants, 12 participants were diagnosed with depression and they were under antidepressant treatment and one had depression but was not receiving antidepressant treatment. 
Table 1. Main characteristics of the sample.

\begin{tabular}{cccc}
\hline & Participant Profile & \\
\hline & \multicolumn{3}{c}{$\mathbf{~ ( \% )}$} \\
\hline & Total $\mathbf{( N ~ = 3 1 )}$ & Depressed (N = 13) & Controls (N = 18) \\
\hline Female & $23(74.2)$ & $10(76.9)$ & $13(72.2)$ \\
Married or cohabiting & $14(45.2)$ & $6(46.2)$ & $8(44.4)$ \\
Employed & $27(87.1)$ & $9(69.2)$ & $18(100)$ \\
High education & $27(87.1)$ & $10(76.9)$ & $17(94.4)$ \\
Urban residents & $24(77.4)$ & $9(69.2)$ & $15(83.3)$ \\
Age & $46.00 \pm 10.23 *$ & $47.77 \pm 10.57 *$ & $44.72 \pm 10.09 *$ \\
BMI & $25.06 \pm 5.63 *$ & $25.75 \pm 8.30 *$ & $24.57 \pm 2.59 *$ \\
Years of possessing a driving license & $22.77 \pm 6.37 *$ & $21.92 \pm 5.31 *$ & $23.39 \pm 7.12 *$ \\
\hline & $*$ Mean, Standard Deviation. &
\end{tabular}

\subsection{Main Findings from the Final Models of Multiple Backward Regressions}

The mean values of patients with depression and healthy controls regarding the five variables for which significant results were found in the regressions are presented in Table 2.

Table 2. Frequencies (\%) or mean values ( \pm standard deviation) of the groups of patients and controls.

\begin{tabular}{ccc}
\hline Variables & Depressed & Controls \\
\hline History of collisions & 4 out of $13(30.8 \%)$ & 4 out of $18(22.3 \%)$ \\
Aggressive driving score 1 & $4.43 \pm 0.79$ & $4.45 \pm 1.01$ \\
Speed SD $^{2}$ & $5.48 \pm 1.24$ & $5.09 \pm 1.42$ \\
Mean LP $^{3}$ & $0.26 \pm 0.82$ & $0.53 \pm 0.89$ \\
Mean of distance from the preceding vehicle (in meters) & $29.57 \pm 60.41$ & $16.71 \pm 21.83$ \\
\hline
\end{tabular}

${ }^{1}$ : Subcale on aggressive driving of the driving stress inventory; ${ }^{2}$ : Standard deviation of speed (inability to keep constant vehicle velocity) in the driving simulator; ${ }^{3}$ : Mean of lateral position; negative numbers: Towards the middle of the road (faster lane); positive numbers: Towards the shoulder (slower lane) in the driving simulator.

The main findings from the final models of multiple backward regressions are presented in Table 3. History of collisions and a high risk score on the DSI subscale for "aggressive driving" were the two variables derived by questionnaires for which significant associations were found with some of the independent variables. From the variables derived from the driving simulator output, those which showed significant associations to independent variables were the ability to maintain a constant vehicle velocity (expressed by the standard deviation of speed), lateral position and the distance from the preceding vehicle.

As shown in Table 3, history of collisions was positively correlated with BMI, with subjects with no collisions in their history having a mean BMI of 24.12 (standard deviation: 2.86) and those with one or more past collisions a mean BMI of 27.79 (SD: 9.94). HADS-D score and sum score of items 7 and 8 of the AIS (next-day consequences of sleep disturbance) were also correlated with number of past collisions. Aggressive driving was positively correlated with the total score on the fatigue severity scale and with total score on sleep disturbances questionnaire and it was negatively correlated to HADS-D score, the sum score of items 7 and 8 of the AIS (next-day consequences of sleep disturbance) and SOFAS (overall functioning) scale. The standard deviation of speed (i.e., the inability to maintain constant velocity) was positively correlated to BMI and AIS total score. Driving towards the middle of the road (faster lane) was positively correlated to the HADS-A score and driving towards the shoulder of the road (slower lane) was positively correlated to the HADS-D score and the sum score of items 7 and 8 of the AIS. The distance from the preceding vehicle was positively correlated to being on drugs with potential hypnotic effects. Those patients who received drugs with potential hypnotic effects kept a mean distance from the preceding vehicle of 73.52m (SD: 103.33) while the mean distance of all other participants was $14.49 \mathrm{~m}$ (SD: 18.57). 
Table 3. Main findings from the final models of multiple backward regressions.

\begin{tabular}{|c|c|c|c|c|c|c|c|c|c|}
\hline \multirow[b]{2}{*}{ Dependent Variables } & \multicolumn{9}{|c|}{ Independent Variables } \\
\hline & BMI $^{1}$ & HADSD $^{2}$ & HADSA $^{3}$ & AIS $^{4}$ & AIS7-8 5 & FSS $^{6}$ & SOFAS ${ }^{7}$ & $\mathrm{SD}^{8}$ & DRUGS $^{9}$ \\
\hline History of Collisions & $\begin{array}{l}\beta=0.073 \\
\mathfrak{p}=0.003\end{array}$ & $\begin{array}{l}\beta=0.104 \\
p=0.001\end{array}$ & & & $\begin{array}{l}\beta=0.279 \\
\mathfrak{p}=0.002\end{array}$ & & & & \\
\hline Aggressive Driving a & & $\begin{array}{l}\beta=-0.101 \\
p=0.028\end{array}$ & & & $\begin{array}{c}\beta=-0.372 \\
p=0.009\end{array}$ & $\begin{array}{l}\beta=0.040 \\
p=0.002\end{array}$ & $\begin{array}{c}\beta=-0.067 \\
p=0.012\end{array}$ & $\begin{array}{l}\beta=0.157 \\
p=0.035\end{array}$ & \\
\hline Speed SD ${ }^{b}$ & $\begin{array}{l}\beta=0.110 \\
p=0.013\end{array}$ & & & $\begin{array}{l}\beta=0.183 \\
p=0.021\end{array}$ & & & & & \\
\hline Mean LP ${ }^{c}$ & & $\begin{array}{l}\beta=0.121 \\
p=0.026\end{array}$ & $\begin{array}{c}\beta=-0.128 \\
p=0.017\end{array}$ & & $\begin{array}{l}\beta=0.298 \\
p=0.041\end{array}$ & & & & \\
\hline Mean distance $^{d}$ & & & & & & & & & $\begin{array}{l}\beta=590.27 \\
p=0.007\end{array}$ \\
\hline
\end{tabular}




\section{Discussion}

Based on our results, it was shown that depression, as it was assessed by HADS-D on the day of the experiment, was positively correlated to a history of road collisions $(p=0.001)$. The number of past collisions was also positively correlated with body mass index $(p=0.003)$ and the next-day consequences of sleep disturbance (low functioning and somnolence, sum score of items 7 and 8 of the AIS) $(p=0.002)$. Similar to our findings relating to depression, a study has found that, independent of the intensity of depression (mild, moderate, severe), the probability for depressive patients causing collisions is 2.4 times than that of the non-depressed [13]. Regarding somnolence and low daytime functioning due to sleep disturbance, our findings are in accordance with studies $[1,26]$ which have provided evidence that daytime somnolence is strongly positively correlated with collisions. High BMI has also been found to be a risk factor for collisions [2], also in patients with obstructive sleep apnea [27].

Aggression during driving (as assessed by DSI) was negatively correlated to depression; responses of the control group showed higher aggressive driving than those of depressed patients. On the other hand, driving aggression showed a strong positive correlation with the variables fatigue and sleep disturbances ( $p=0.002$ and $p=0.035$, respectively). The more the participants reported fatigue and disturbed sleep, the more aggression during driving was found through the questionnaires that assessed driving behaviour. Research on collisions that were caused due to sleep disturbances has shown that, similar to our findings, daytime sleepiness was found to be the most important risk factor $[1,2,28]$. These findings imply that poor sleep quality may lead to mismanagement of emotions and that may eventually contribute to collisions. In a meta-analysis study of Zhang et al. [29] aggressive driving was strongly correlated to driving anger, which can lead to frustration and cognitive difficulties (attention, reasoning, judgment and decision making) during driving.

The reduced ability to maintain constant vehicle velocity was positively correlated to body mass index and to the total score in the AIS ( $p=0.013$ and $p=0.021$, respectively). Garbarino et al. [4] found also that insomnia is positively correlated to road accidents. Our findings show that insomnia affects the ability to maintain constant vehicle velocity, which might lead to collisions since the driver is not adequately controlling the vehicle's speed. Regarding BMI, research shows that it is a risk factor for traffic accidents [2,30]. The main connection of BMI to road safety is that a high BMI is strongly associated with the risk for obstructive sleep apnea and the presence of excessive daytime sleepiness [31].

Anxiety was found to be associated with a trend to drive towards the middle of the road (LP-faster lane) $(\mathrm{p}=0.017)$. To the contrary, a tendency to drive towards the shoulder of the road (LP-slower lane) was associated with the intensity of depression $(p=0.026)$ and next-day consequences of sleep disturbance (low functioning and somnolence, sum score of items 7 and 8 on AIS) (p=0.041) denoting that drivers were driving more cautiously.

Similarly, a strong positive correlation was found between the distance from the preceding vehicle and being on drugs with potential hypnotic effects $(p=0.007)$. It seems that participants who were under this kind of medication were keeping a larger safety distance from the preceding vehicle. The fact that depression, consequences of sleep disturbances and use of drugs with possible hypnotic activity lead to a more a "conservative" way of driving could be the result of an effort on the part of the patients to balance the dangers created by the consequences of depression and sleepiness while driving. This is a possible explanation why, in the study of Brunnauer et al. [10], which took place in a real driving environment (on-road driving test) and not in a driving simulator, no difference in driving skills was found between groups under medication and healthy controls.

The above findings, if supported by future studies, suggest that the main reason for any driving impairment of depressed patients is depression per se, its symptoms and its severity. The consequences of treatment, even with drugs which are considered to cause somnolence, do not seem to compromise safety. It should be, thus, understood that it is more important for road safety that patients with depression receive adequate therapeutic interventions for their condition, in spite of fears that the 
treatment might compromise their driving. This suggestion, however, is quite preliminary, given the small sample on which this study is based. Finally, clinical judgment should always be used in the decision whether to suggest to the patient that they avoid driving.

\section{Limitations}

Our sample being relatively small did not allow for a more detailed analysis to deal with confounding issues. Thus, the question if it is the comorbidities of depression (obesity, lack of sleep, etc.) that are associated with driving impairment or depression itself could not be addressed.

The generalization of the findings of the present study may be limited, since no information was available on how much the participants drive daily/weekly/monthly. Thus, it is difficult to know how far our sample is representative of the population at large or depressive patients for whom, in addition, there are no reliable data on their driving habits.

\section{Conclusions}

In this study, we examined driving performance in depression, taking into account the symptoms of anxiety and sleep disorders. The study was based on questionnaires and on driving in a driving simulator. The findings show that depression, sleep and anxiety measures correlated with various aspects of driving behaviour. Patients may have been using compensatory mechanisms to counteract some of the effects of depression and its treatment on their driving performance. These findings should be replicated in further studies in which questions of comorbidities, confounding factors and generalization of results need also to be addressed. Such a progress in our understanding of the field could lead to the development of road safety policy recommendations regarding depression and its treatment.

Author Contributions: Conceptualization, V.T., D.D. and M.P.; Data curation, V.T. and D.D.; Formal analysis, V.T. and D.D.; Investigation, V.T.; Methodology, V.T. and D.D.; Project administration, V.T.; Resources, M.B. and M.P.; Supervision, D.D.; Validation, V.T., D.D., M.B. and M.P.; Visualization, V.T.; Writing-original draft, V.T.; Writing-review and editing, D.D. and M.P.

Funding: This research received no external funding. The study has been conducted in the frame of an MSc Degree "Promotion of Mental Health-Prevention of Psychiatric Disorders", Medical School, National and Kapodistrian University of Athens.

Acknowledgments: Many thanks to the psychiatrists Th. Adrakta and E. Grinakis who recruited four patients for the study.

Conflicts of Interest: The authors declare no conflict of interest regarding this work.

Research Ethics: All participants gave their informed consent for inclusion before they participated in this study. The study was conducted in accordance with the Declaration of Helsinki and the protocol was approved by the Ethics Committee of University General Hospital of Heraklion (798/20/25-7-2018).

\section{References}

1. Inoue, Y.; Komada, Y. Sleep loss, sleep disorders and driving accidents. Sleep Biol. Rythms 2014, 12, 96-105. [CrossRef]

2. Johnson, K.D.; Patel, S.R.; Baur, D.M.; Edens, E.; Sherry, P.; Malhotra, A.; Kales, S.N. Association of sleep habits with accidents and near misses in United States transportation operators. J. Occup. Environ. Med. 2014, 56, 510-515. [CrossRef] [PubMed]

3. Barger, L.K.; Rajaratham, S.M.; Wang, W.; O’Brien, C.S.; Sullivan, J.P.; Qadri, S.; Lockley, S.W.; Czeisler, C.A. Common sleep disorders increase risk of motor vehicle crashes and Adverse Health Outcomes in Firefighters. J. Clin. Sleep Med. 2015, 11, 233-240. [CrossRef] [PubMed]

4. Garbarino, S.; Magravita, N.; Guglielmi, O.; Maestri, M.; Dini, G.; Bersi, F.M.; Toletone, A.; Chiorri, C.; Durando, P. Insomnia is associated with road accidents. Further evidence from a study on truck drivers. PLoS ONE 2017, 12, e0187256. [CrossRef] [PubMed]

5. Wittchen, H.-U.; Mühlig, S.; Beesdo, K. Mental disorders in primary care. Dialogues Clin. Neurosci. 2003, 5, 115-128. 
6. WHO. The Global Burden of Disease: 2004 Update; World Health Organization: Geneva, Switzerland, 2008; pp. 1-160.

7. Van der Sluiszen, N.N.; Wingen, M.; Vermeeren, A.; Vinckenbosch, F.; Jongen, S.; Ramaekers, J.G. Driving performance of depressed patients who are untreated or receive long-term antidepressant (SSRI/SNRI) treatment. Pharmacopsychiatry 2017, 50, 182-188. [CrossRef]

8. Marazziti, D.; Consoli, G. Cognitive impairment in major depression. Eur. J. Pharmacol. 2010, 626, 83-86. [CrossRef]

9. Ferentinos, P.; Kontaxakis, V.; Havaki-Kontaxaki, B.; Paparrigopoulos, T.; Dikeos, D.; Ktonas, P.; Soldatos, C. Sleep disturbances in relation to fatigue in major depression. J. Psychosom. Res. 2009, 66, 37-42. [CrossRef]

10. Brunnauer, A.; Buschert, V.; Fric, M.; Distler, G.; Sander, K.; Segmiller, F.; Zwanzger, P.; Laux, G. Driving performance and psychomotor function in depressed patients treated with Agomelatine or Venlafaxine. Pharmacopsychiatry 2015, 48, 65-71. [CrossRef]

11. Chliaoutakis, J.E.; Demakakos, P.; Tzamalouka, G.; Bakou, V.; Koumaki, M.; Darviri, C. Aggressive behaviour while driving as predictor of self-reported road crashes. J. Saf. Res. 2002, 33, 431-443. [CrossRef]

12. Taubman-Ben-Ari, O.; Mikulincer, M.; Gillath, O. The multidimensional driving style inventory-Scale construct and validation. Accid. Anal. Prev. 2004, 36, 323-332. [CrossRef]

13. Alavi, S.S.; Mohammadi, M.R.; Souri, H.; Kalhori, S.M.; Jannatifard, F.; Sepahbodi, G. Personality, driving behaviour and mental disorders factors as predictors of road traffic accidents based on logistic regression. Iran J. Med. Sci. 2017, 42, 24-31. [PubMed]

14. Van der Sluiszen, N.N.; Vermeeren, A.; Jongen, S.; Vinckenbosch, F.; Ramaekers, J.G. Influence of Long-Term Benzodiazepine use on Neurogognitive Skills Related on Driving Performance in Patients Populations: A Review. Pharmacopsychiatry 2017, 50, 189-196. [CrossRef] [PubMed]

15. Blana, E. Driving Simulator Validation Studies: A Literature Review; Working Paper; University of Leeds: Leeds, UK, 1996.

16. Helland, A.; Jenssen, G.D.; Lervåg, L.E.; Westin, A.A.; Moen, T.; Sakshaug, K.; Lydersen, S.; Mørland, J.; Slørdal, L. Comparison of driving simulator performance with real driving after alcohol intake: A randomized, single blind, placebo-controlled, cross-over trial. Accid. Anal. Prev. 2013, 53, 9-16. [CrossRef] [PubMed]

17. Papadakaki, M.; Tzamalouka, G.; Gnardellis, C.; Lajunen, T.J.; Chliaoutakis, J. Driving performance while using a mobile phone: A simulation study of Greek professional drivers. Transp. Res. (Part F) 2016, 38, 164-170. [CrossRef]

18. Zigmond, S.A.; Snaith, R.P. The hospital anxiety and depression scale. Acta Psychiatr. Scand. 1983, 67, 361-370. [CrossRef]

19. Soldatos, C.R.; Dikeos, D.G.; Paparrigopoulos, T. Athens Insomnia Scale: Validation of an instrument based on ICD-10 criteria. J. Psychosom. Res. 2000, 48, 555-560. [CrossRef]

20. WHO. The ICD-10 Classification of Mental and Behavioural Disorders: Clinical Descriptions and Diagnostic Guidelines; World Health Organization: Geneva, Switzerland, 1992.

21. Krupp, L.B.; LaRocca, N.G.; Muir-Nash, J.; Steinberg, A.D. The fatigue severity scale. Application to patients with multiple Sclerosis and Systemic Lupus Erythematosus. Arch. Neurol. 1989, 46, 1121-1123. [CrossRef]

22. Goldman, H.; Skodol, A.; Lave, T. Revising Axis V for DSM-IV: A Review of Measures of Social Functioning. Am. J. Psychiatry 1992, 149, 1148-1156. [CrossRef]

23. Glendon, A.I.; Dorn, L.; Matthews, G.; Gulian, E.; Davies, D.R.; Debney, L.M. Reliability of the driving behaviour inventory. Ergonomics 1993, 36, 719-726. [CrossRef]

24. Qu, W.; Zhang, Q.; Zhao, W.; Zhang, K.; Ge, Y. Validation of the Driver Stress Inventory in China: Relationship with dangerous driving behaviours. Accid. Anal. Prev. 2016, 87, 50-58. [CrossRef] [PubMed]

25. Hirsch, P.; Choukou, M.-A.; Bellavance, F. Transfer of training in basic control skills from truck simulator to real truck. Transp. Res. Rec. 2017, 2637, 67-73. [CrossRef]

26. Karimi, M.; Hedner, J.; Lombardi, C.; McNicholas, W.T.; Penzel, T.; Riha, R.L.; Rodenstein, D.; Grote, L.; Esada Study Group; Barbé, F.; et al. Driving habits and risk factors for traffic accidents among sleep apnea patients- a European multi-centre cohort study. J. Sleep Res. 2014, 23, 689-699. [CrossRef] [PubMed]

27. Nena, E.; Steiropoulos, P.; Tsara, V. Obstructive sleep apnea as a risk factor for road traffic accidents. Arch. Hell. Med. 2010, 27, 128-130. (In Greek)

28. Al Lawati, N.; Patel, S.; Ayas, N. Epidemiology, Risk factors and consequences of obstructive sleep apnea and short sleep duration. Prog. Cardiovasc. Dis. 2009, 51, 285-293. [CrossRef] 
29. Zhang, T.; Chan, A. The association between driving anger and driving outcomes: A meta-analysis of evidence from the past twenty years. Accid. Anal. Prev. 2016, 90, 50-62. [CrossRef]

30. Philip, P.; Chaufton, C.; Orriols, L.; Lagarde, E.; Amoros, E.; Laumon, B.; Akerstedt, T.; Taillard, J.; Sagaspe, P. Complaints of poor sleep and risk of traffic accidents: A population-based case-control study. PLoS ONE 2014, 9, e114102. [CrossRef]

31. Kales, S.N.; Straubel, M.G. Obstructive sleep apnea in North American commercial drivers. Ind. Health 2014, 52, 13-24. [CrossRef]

(C) 2019 by the authors. Licensee MDPI, Basel, Switzerland. This article is an open access article distributed under the terms and conditions of the Creative Commons Attribution (CC BY) license (http://creativecommons.org/licenses/by/4.0/). 